UDK 528.14

\title{
JONOSFEROS İTAKA GPS STYGŲ KOORDINAČIŲ PRIEAUGIAMS, TAIKANT NEŠLIO FAZIŲ DVIGUBUOSIUS SKIRTUMUS
}

\author{
Jonas Skeivalas \\ Geodezijos ir kadastro katedra, Vilniaus Gedimino technikos universitetas, \\ Saulètekio al. 11, LT-10223 Vilnius, Lietuva, \\ el.paštas: Jonas.Skeivalas@ap.vgtu.lt
}

Iteikta 200612 08, priimta 20070330

\begin{abstract}
Santrauka. Analizuojamas nešlio fazių dvigubujų skirtumų taikymas jonosferos įtakai eliminuoti, apdorojant dviejų nešlio dažnių GPS imtuvų matavimų rezultatus. Skaičiavimų procedūrose taikomos nešlio fazių dvigubuju skirtumų išraiškos su papildomais parametrais jonosferos įtakai eliminuoti. Jonosferos itaka eliminuojama sprendžiant mažiausiujjų kvadratų metodu redukuotas kiekvienos epochos nešlio fazių dvigubujų skirtumų parametrines lygtis. Parametrinių lygčių sistema sprendžiama sudarant papildomas sąlygines lygtis. Sprendinio rezultatų patikimumui ivvertinti siūlomos kovariacijų matricų formulès.
\end{abstract}

Reikšminiai žodžiai: GPS, jonosferos įtaka, nešlio fazių dvigubieji skirtumai.

\section{Ivadas}

GPS matavimo rezultatu tikslumui įtakos turi daugelis veiksnių: dirbtinių Žemès palydovų (DŽP) efemeridžių klaidos, DŽP geometrija, GPS imtuvų ir palydovų laikrodžių klaidos, signalų interferencija ir atspindžiai, troposfera, jonosfera bei kitų šaltinių lemiamos klaidos. GPS matavimų tikslumui didžiausia troposfera ir jonosfera įtaka. Nemaža autorių ivvairiais aspektais analizavo ir analizuoja šias matavimų klaidas, atitinkamų dydžių ir parametrų nustatymo tikslumą, skaičiavimo algoritmų sudarymą [1-11]. Dažniausiai jonosferos itakai matavimo rezultatams eliminuoti taikomi dviejų nešlio dažnių tiesiniai modeliai, o troposferos įtakai sumažinti - atitinkami netiesiniai modeliai.

Straipsnyje siūlomas metodas pagrịstas koordinačių prieaugių sąlyginių lygčių su papildomais parametrais $\gamma$ taikymu koordinačiu prieaugių sistemingosioms klaidoms eliminuoti. Klaidos dèl troposferos ir jonosferos įtakos yra sisteminio pobūdžio. Taikant papildomus parametrus matavimų klaidų sistemingoji komponentė eliminuojama patikimiau.

\section{Teoriniai teiginiai}

Pagal GPS kanalų $L_{1}$ ir $L_{2}$ matavimo rezultatus sudarytų nešlio fazių dvigubujų skirtumų reikšmès nesutampa dèl jonosferos, troposferos lemiamu ir kitu matavimo klaidų. Kadangi dèl jonosferos ir kitų šaltinių itakos atsirandančios matavimo klaidos turi atsitiktines ir sistemingąsias komponentes, tai matavimo rezultatams apdoroti taikysime mažiausiujuc kvadratų metodą bei papildomus parametrus sistemingosioms klaidų komponentėms eliminuoti.
Pagrindinè nešlio fazių dvigubujų skirtumų modelio lygtis:

$$
\Phi_{i j, c i k l .}^{k l}(t)=\frac{1}{\lambda} S_{i j}^{k l}(t)-N_{i j, c i k l}^{k l}+\delta \Phi_{i j}^{k l}(t)
$$

čia $\Phi_{i j, c i k l}^{k l}(t)$ - fazių dvigubasis skirtumas pagal dviejų imtuvų $-i$ ir $j$ matavimų rezultatus iš dviejų palydovu $-k$ ir $l$ laiko momentu (epocha) $t, S_{i j}^{k l}(t)-$ atitinkamų geometrinių atstumų dvigubasis skirtumas, $N_{i j, c i k l}^{k l}$ - pradinių sveikujų ciklų skaičiaus dvigubasis skirtumas, $\lambda \rightarrow \lambda_{1}$ arba $\lambda_{2}-$ nešlio kanalų $-L 1$ arba $L 2$ bangos ilgis; $\delta \Phi_{i j}^{k l}(t)$ - kitu klaidų šaltinių sumine itaka.

Redukavę fazių ciklų lygybę (1) ilgio vienetais, taikydami abu nešlio bangos ilgius $-\lambda_{1}$ ir $\lambda_{2}$, gauname:

$$
\left.\begin{array}{l}
\Phi_{1, i j}^{k l}(t)=S_{i j}^{k l}(t)-N_{1, i j}^{k l}+\delta \Phi_{1, i j}^{k l}(t) \\
\Phi_{2, i j}^{k l}(t)=S_{i j}^{k l}(t)-N_{2, i j}^{k l}+\delta \Phi_{2, i j}^{k l}(t)
\end{array}\right\},
$$

čia $\Phi_{1, i j}^{k l}(t)=\lambda_{1} \Phi_{1, i j, c i k l .}^{k l}(t), \quad \Phi_{2, i j}^{k l}(t)=\lambda_{2} \Phi_{2, i j, c i k l .}^{k l}(t)$, $N_{1, i j}^{k l}(t)=\lambda_{1} N_{1, i j, c i k l}^{k l}, \quad N_{2, i j}^{k l}(t)=\lambda_{2} N_{2, i j, c i k l}^{k l}, N_{1, i j}^{k l}(t)=$ $N_{2, i j}^{k l}(t)=N_{i j}^{k l}(t)$.

Supaprastinant išraišką, jos narys $\delta \Phi_{i j}^{k l}(t)$ nerašomas, nes jo reikšmè gali būti nustatoma pagal atitinkamus modelius. 
Vienos sesijos $n$ epochų GPS išmatuotieji nešlio fazių dvigubieji skirtumai apdorojami mažiausiuju kvadratų metodu, taikant papildomus parametrus jonosferos klaidu sistemingosioms komponentems eliminuoti. Galima parašyti šią parametrinių lygčių sistemą:

$\tilde{\Phi}_{1, i j}^{k l}\left(t_{i}\right)=a_{i j 1}^{k l}\left(t_{i}\right) \Delta \tilde{X}_{i j}+a_{i j 2}^{k l}\left(t_{i}\right) \Delta \tilde{Y}_{i j}+a_{i j 3}^{k l}\left(t_{i}\right) \Delta \tilde{Z}_{i j}-$ $N_{i j}^{k l}+\gamma_{1, i j}^{k l}$

$\left.\tilde{\Phi}_{2, i j}^{k l}\left(t_{i}\right)=a_{i j 1}^{k l}\left(t_{i}\right) \Delta \tilde{X}_{i j}+a_{i j 2}^{k l}\left(t_{i}\right) \Delta \tilde{Y}_{i j}+a_{i j 3}^{k l}\left(t_{i}\right) \Delta \tilde{Z}_{i j}-\right\}$, $N_{i j}^{k l}+\gamma_{2, i j}^{k l}$

čia $t_{i}=t_{1}, t_{2}, \ldots, t_{n} ; \quad \tilde{\Phi}_{1, i j}^{k l}\left(t_{i}\right)=\Phi_{1, i j}^{k l}\left(t_{i}\right)+v_{1, i j}^{k l}\left(t_{i}\right)$,

$\tilde{\Phi}_{2, i j}^{k l}\left(t_{i}\right)=\Phi_{2, i j}^{k l}\left(t_{i}\right)+v_{2, i j}^{k l}\left(t_{i}\right), \quad \Delta \tilde{X}_{i j}, \Delta \tilde{Y}_{i j}, \Delta \tilde{Z}_{i j}-$ išlyginti koordinačių prieaugiai; $\gamma_{1, i j}^{k l}, \gamma_{2, i j}^{k l}$ - atitinkamai $L 1$ arba $L 2$ kanalu jonosferos sisteminguju klaidų skirtuminès komponentès; $v_{1, i j}^{k l}\left(t_{i}\right), \quad v_{2, i j}^{k l}\left(t_{i}\right)$ - atitinkamai $L 1$ ir $L 2$ kanalu atsitiktinių jonosferos ir kitu matavimo klaidų skirtuminès pataisos.

Koeficientu $a_{i j 1}^{k l}\left(t_{i}\right), a_{i j 2}^{k l}\left(t_{i}\right), a_{i j 3}^{k l}\left(t_{i}\right)$ išraiškos:

$$
\left.\begin{array}{l}
a_{i j 1}^{k l}\left(t_{i}\right)=\frac{X^{k}\left(t_{i}\right)-\bar{X}_{i j}}{\bar{S}_{i j}^{k}\left(t_{i}\right)}-\frac{X^{l}\left(t_{i}\right)-\bar{X}_{i j}}{\bar{S}_{i j}^{l}\left(t_{i}\right)} \\
a_{i j 2}^{k l}\left(t_{i}\right)=\frac{Y^{k}\left(t_{i}\right)-\bar{Y}_{i j}}{\bar{S}_{i j}^{k}\left(t_{i}\right)}-\frac{Y^{l}\left(t_{i}\right)-\bar{Y}_{i j}}{\bar{S}_{i j}^{l}\left(t_{i}\right)} \\
a_{i j 3}^{k l}\left(t_{i}\right)=\frac{Z^{k}\left(t_{i}\right)-\bar{Z}_{i j}}{\bar{S}_{i j}^{k}\left(t_{i}\right)}-\frac{Z^{l}\left(t_{i}\right)-\bar{Z}_{i j}}{\bar{S}_{i j}^{l}\left(t_{i}\right)}
\end{array}\right\}
$$

čia $\bar{X}_{i j}=1 / 2\left(X_{i}+X_{j}\right), \quad \bar{Y}_{i j}=1 / 2\left(Y_{i}+Y_{j}\right)$,

$\bar{Z}_{i j}=1 / 2\left(Z_{i}+Z_{j}\right), \bar{S}_{i j}^{k}\left(t_{i}\right)=1 / 2\left\{S_{i}^{k}\left(t_{i}\right)+S_{j}^{k}\left(t_{i}\right)\right\}$,

$\bar{S}_{i j}^{l}\left(t_{i}\right)=1 / 2\left\{S_{i}^{l}\left(t_{i}\right)+S_{j}^{l}\left(t_{i}\right)\right\}$.

Apytikrès koordinačiu $X_{i}, Y_{i}, Z_{i}, X_{j}, Y_{j}, Z_{j}$ bei atstumu $S_{i}^{k}\left(t_{i}\right), \quad S_{j}^{k}\left(t_{i}\right), \quad S_{i}^{l}\left(t_{i}\right), \quad S_{j}^{l}\left(t_{i}\right)$ reikšmès gaunamos pagal GPS kodinių matavimų rezultatus.

Sudaromos parametrinès pataisų lygtys:

$$
\left.\begin{array}{l}
V_{1, i j}^{k l}\left(t_{i}\right)=a_{i j 1}^{k l}\left(t_{i}\right) \Delta \tilde{X}_{i j}+a_{i j 2}^{k l}\left(t_{i}\right) \Delta \tilde{Y}_{i j}+a_{i j 3}^{k l}\left(t_{i}\right) \Delta \tilde{Z}_{i j}- \\
N_{i j}^{k l}+\gamma_{1, i j}^{k l}-\Phi_{1, i j}^{k l}\left(t_{i}\right) \\
V_{2, i j}^{k l}\left(t_{i}\right)=a_{i j 1}^{k l}\left(t_{i}\right) \Delta \tilde{X}_{i j}+a_{i j 2}^{k l}\left(t_{i}\right) \Delta \tilde{Y}_{i j}+a_{i j 3}^{k l}\left(t_{i}\right) \Delta \tilde{Z}_{i j}- \\
N_{i j}^{k l}+\gamma_{2, i j}^{k l}-\Phi_{2, i j}^{k l}\left(t_{i}\right)
\end{array}\right\} .
$$

Priimant signalus iš keturių palydovu $(1,2,3$ ir 4$)$ dviem imtuvais $-i$ ir $j$, tos pačios $i$-osios epochos pataisų lygčių sistema gaunama matricų pavidalu:

$$
\boldsymbol{V}_{i j}\left(t_{i}\right)=\boldsymbol{A}_{i j}\left(t_{i}\right) \tilde{\boldsymbol{T}}_{i j}+\boldsymbol{L}_{i j}\left(t_{i}\right)
$$

čia $V_{i j}\left(t_{i}\right)-i$-osios epochos fazių dvigubujų skirtumų pataisų vektorius, $\boldsymbol{A}_{i j}\left(t_{i}\right)$ - pataisų lygčių koeficientų matrica, $\tilde{\boldsymbol{T}}_{i j}-$ parametru vektorius, $\boldsymbol{L}_{i j}\left(t_{i}\right)-i$-osios epochos pataisų lygčių laisvujų narių vektorius.

Sistemos matricų išraiškos:

$$
\begin{gathered}
\boldsymbol{V}_{i j}\left(t_{i}\right)=\left(v_{1, i j}^{12}\left(t_{i}\right), v_{1, i j}^{13}\left(t_{i}\right), v_{1, i j}^{14}\left(t_{i}\right), v_{2, i j}^{12}\left(t_{i}\right), v_{2, i j}^{13}\left(t_{i}\right),\right. \\
\left.v_{2, i j}^{14}\left(t_{i}\right)\right)^{T},
\end{gathered}
$$

$$
\begin{gathered}
\tilde{\boldsymbol{T}}_{i j}=\left(\Delta \tilde{X}_{i j}, \Delta \tilde{Y}_{i j}, \Delta \tilde{Z}_{i j}, N_{i j}^{12}, N_{i j}^{13}, N_{i j}^{14}, \gamma_{1, i j}^{12}, \gamma_{1, i j}^{13},\right. \\
\left.\gamma_{1, i j}^{14}, \gamma_{2, i j}^{12}, \gamma_{2, i j}^{13}, \gamma_{2, i j}^{14}\right)^{T},
\end{gathered}
$$

$$
\begin{gathered}
\boldsymbol{L}_{i j}\left(t_{i}\right)=-\left(\Phi_{1, i j}^{12}\left(t_{i}\right) ; \Phi_{1, i j}^{13}\left(t_{i}\right) ; \Phi_{1, i j}^{14}\left(t_{i}\right) ; \Phi_{2, i j}^{12}\left(t_{i}\right) ;\right. \\
\left.\Phi_{2, i j}^{13}\left(t_{i}\right) ; \Phi_{2, i j}^{14}\left(t_{i}\right)\right)^{T}
\end{gathered}
$$

$$
\boldsymbol{A}_{i j}\left(t_{i}\right)=\left(\begin{array}{cccc}
\boldsymbol{A}_{i j}^{\prime} & -\boldsymbol{E} & \boldsymbol{E} & 0 \\
\boldsymbol{A}_{i j}^{\prime} & -\boldsymbol{E} & 0 & \boldsymbol{E}
\end{array}\right),
$$

$$
\boldsymbol{A}_{i}^{\prime}=\left(\begin{array}{lll}
a_{i j 1}^{12} & a_{i j 2}^{12} & a_{i j 3}^{12} \\
a_{i j 1}^{13} & a_{i j 2}^{13} & a_{i j 3}^{13} \\
a_{i j 1}^{14} & a_{i j 2}^{14} & a_{i j 3}^{14}
\end{array}\right),
$$

$\boldsymbol{E}$ - vienetinè matrica, kurios matmenys $3 \times 3$.

Nagrinèsime matavimu varianta, kai matavimams naudojami trys imtuvai, ir išmatuotosios stygos sudaro uždarą trikampi. Šiame variante prie trijų stygų parametrinių pataisų lygčių sistemos, kai kiekvienos stygos lygčių sistema yra (6) pavidalo, prijungiame tris papildomas sąlygines koordinačių prieaugių lygtis:

$$
\left.\begin{array}{l}
\Delta \tilde{X}_{12}+\Delta \tilde{X}_{23}+\Delta \tilde{X}_{31}=0 \\
\Delta \tilde{Y}_{12}+\Delta \tilde{Y}_{23}+\Delta \tilde{Y}_{31}=0 \\
\Delta \tilde{Z}_{12}+\Delta \tilde{Z}_{23}+\Delta \tilde{Z}_{31}=0
\end{array}\right\},
$$

čia $i j=12,23,31-$ trikampio stygu numeracija.

$i$-osios epochos bendroji trikampio stygu pataisu lygčiu sistema, kai signalai priimami iš keturiu palydovų, ir kiekvienai stygai naudota du imtuvai:

$$
\boldsymbol{V}\left(t_{i}\right)=\boldsymbol{A}\left(t_{i}\right) \tilde{\boldsymbol{T}}+\boldsymbol{L}\left(t_{i}\right)
$$

$$
\begin{aligned}
& \boldsymbol{V}\left(t_{i}\right)=\left(\boldsymbol{V}_{12}^{\boldsymbol{T}}\left(t_{i}\right), \boldsymbol{V}_{23}^{\boldsymbol{T}}\left(t_{i}\right), \boldsymbol{V}_{31}^{\boldsymbol{T}}\left(t_{i}\right)\right)^{\boldsymbol{T}}, \tilde{\boldsymbol{T}}=\left(\tilde{\boldsymbol{T}}_{12}^{\boldsymbol{T}}, \tilde{\boldsymbol{T}}_{23}^{\boldsymbol{T}}, \tilde{\boldsymbol{T}}_{31}^{\boldsymbol{T}}\right)^{\boldsymbol{T}}, \\
& \boldsymbol{L}\left(t_{i}\right)=\left(\boldsymbol{L}_{12}^{\boldsymbol{T}}\left(t_{i}\right), \boldsymbol{L}_{23}^{\boldsymbol{T}}\left(t_{i}\right), \boldsymbol{L}_{31}^{\boldsymbol{T}}\left(t_{i}\right)\right)^{\boldsymbol{T}} .
\end{aligned}
$$


Matrica $\boldsymbol{A}\left(t_{i}\right)$ yra kvazidiagonalioji:

$$
\boldsymbol{A}\left(t_{i}\right)=\left(\begin{array}{ccc}
\boldsymbol{A}_{12}\left(t_{i}\right) & \mathbf{0} & \mathbf{0} \\
\mathbf{0} & \boldsymbol{A}_{23}\left(t_{i}\right) & \mathbf{0} \\
\mathbf{0} & \mathbf{0} & \boldsymbol{A}_{31}\left(t_{i}\right)
\end{array}\right)
$$

Matricos $\boldsymbol{A}\left(t_{i}\right)$ blokinès dalys sudaromos pagal formulę (10), kai $i j \rightarrow 12,23,31$.

Papildomų sąlyginių lygčių sistemos (12) išraiška matricu pavidalu:

$$
\boldsymbol{A}_{s} \tilde{\boldsymbol{T}}=\mathbf{0}
$$

čia $A_{s}=\left(\begin{array}{l}\boldsymbol{E} 0 \\ \mathbf{E}\end{array} \mathbf{0} \boldsymbol{E} \mathbf{0}\right)$ - sąlyginių lygčių koeficientų matrica, $\boldsymbol{E}$ - vienetinè matrica, kurios matmenys $3 \times 3$; $\mathbf{0}$ - nulinè matrica, ir jos matmenys $3 \times 9$.

$n_{e}$ epochų $L 1$ ir $L 2$ kanalų fazių dvigubiesiems skirtumams apdoroti rašome pataisų lygčių sistemą blokiniu pavidalu, prijungdami sąlyginių lygčių sistemą (15):

$$
\left.\begin{array}{l}
\boldsymbol{V}=\boldsymbol{A} \tilde{\boldsymbol{T}}+\boldsymbol{L} \\
\boldsymbol{A}_{\boldsymbol{s}} \tilde{\boldsymbol{T}}=0
\end{array}\right\}
$$

čia

$$
\begin{aligned}
& \boldsymbol{V}=\left(\boldsymbol{V}^{\boldsymbol{T}}\left(t_{1}\right), \boldsymbol{V}^{\boldsymbol{T}}\left(t_{2}\right), \ldots, \boldsymbol{V}^{\boldsymbol{T}}\left(t_{n_{e}}\right)\right)^{\boldsymbol{T}}, \\
& \boldsymbol{A}=\left(\boldsymbol{A}^{\boldsymbol{T}}\left(t_{1}\right), \boldsymbol{A}^{\boldsymbol{T}}\left(t_{2}\right), \ldots, \boldsymbol{A}^{\boldsymbol{T}}\left(t_{n_{e}}\right)\right)^{\boldsymbol{T}}, \\
& \boldsymbol{L}=\left(\boldsymbol{L}^{\boldsymbol{T}}\left(t_{1}\right), \boldsymbol{L}^{\boldsymbol{T}}\left(t_{2}\right), \ldots, \boldsymbol{L}^{\boldsymbol{T}}\left(t_{n_{e}}\right)\right)^{\boldsymbol{T}} .
\end{aligned}
$$

Spręsdami lygčių sistemą (16) taikome mažiausiuju kvadratų metodo sąlyga

$$
\Phi=V^{T} P V+2 k^{T} A_{s} \tilde{T}=\min
$$

Toliau gauname

$$
\frac{\partial \Phi}{\partial \tilde{\boldsymbol{T}}}=2 \boldsymbol{A}^{\boldsymbol{T}} \boldsymbol{P} \boldsymbol{V}+2 \boldsymbol{A}_{s}^{T} \boldsymbol{k}=0
$$

čia $\boldsymbol{P}$ - nešlio faziu dvigubuju skirtumų svoriu matrica $\left(6 n_{e} \times 6 n_{e}\right), \quad k-$ koreliatų (Lagranžo daugiklių) vektorius $(r \times 1), \quad r=3$ - sąlyginių lygčių skaičius. Svorių matrica $\boldsymbol{P}$ sudaroma pagal metodika, pateiktą straipsnyje [11].

I lygybę (17) įrašę $\boldsymbol{V}$ išraišką iš sistemos (16) ir prijungę sąlyginių lygčių sistemą (15) gauname jungtinę lygčių sistemą:

$$
\left.\begin{array}{l}
\boldsymbol{N} \tilde{\boldsymbol{T}}+A_{s}^{T} k+\omega=0 \\
A_{s} \tilde{\boldsymbol{T}}=0
\end{array}\right\}
$$

čia $N=A^{T} P A, \omega=A^{T} P L$.

Šios sistemos sprendinys

$$
\tilde{\boldsymbol{T}}_{0}=\left(\begin{array}{c}
\tilde{\boldsymbol{T}} \\
\boldsymbol{k}
\end{array}\right)=\left(\begin{array}{cc}
\boldsymbol{N} & \boldsymbol{A}_{\boldsymbol{s}}^{\boldsymbol{T}} \\
\boldsymbol{A}_{\boldsymbol{s}} & 0
\end{array}\right)^{-1}\left(\begin{array}{c}
\boldsymbol{\omega} \\
0
\end{array}\right)=\boldsymbol{N}_{0}^{-1} \boldsymbol{\omega}_{0}
$$

Atvirkštinei matricai $\boldsymbol{N}_{0}^{-1}$ skaičiuoti taikome blokinę išraišką pagal K. R. Koch metodą [3]:

$$
\boldsymbol{N}_{0}^{-1}=\left(\begin{array}{c|c}
\boldsymbol{N}^{-1}+\boldsymbol{F} \boldsymbol{H}^{-1} \boldsymbol{F}^{\boldsymbol{T}} & -\boldsymbol{F} \boldsymbol{H}^{-1} \\
-\boldsymbol{H}^{-1} \boldsymbol{F}^{\boldsymbol{T}} & \boldsymbol{H}^{-1}
\end{array}\right)=\left(\begin{array}{cc}
\boldsymbol{Q}_{11} & \boldsymbol{Q}_{12} \\
\boldsymbol{Q}_{21} & \boldsymbol{Q}_{22}
\end{array}\right)
$$

čia $F=N^{-1} A_{s}^{T}, H=-A_{s} N^{-1} A_{s}^{T}$.

Lygčių sistemos sprendinys (19) rodo visų trijų trikampio stygu išlygintuju koordinačių prieaugiu $\Delta \tilde{X}_{i j}$, $\Delta \tilde{\boldsymbol{Y}}_{i j}, \Delta \tilde{\boldsymbol{Z}}_{i j}$ reikšmes bei nešlio fazių dvigubujų skirtumų sistemingujų komponenčių $\gamma_{1, i j}^{k l}, \quad \gamma_{2, i j}^{k l}$ reikšmes, kurioms itakos turi jonosfera.

\section{Išlygintųjų parametrų tikslumo įvertinimas}

Mažiausiujų kvadratų metodu pagal formulę (19) apskaičiuotos parametrų ir koreliatų vektoriaus $\tilde{\boldsymbol{T}}_{0}=\left(\tilde{\boldsymbol{T}}^{\boldsymbol{T}}, \boldsymbol{k}^{\boldsymbol{T}}\right)^{\boldsymbol{T}} \quad$ reikšmès tikslumas ịvertinamas kovariacijų matrica $\boldsymbol{K}_{\widetilde{T}_{0}}$ :

$$
\boldsymbol{K}_{\widetilde{\boldsymbol{T}}_{0}}=\boldsymbol{N}_{0}^{-1} \boldsymbol{K}_{\omega_{0}} \boldsymbol{N}_{0}^{-1}
$$

čia $\boldsymbol{K}_{\omega_{0}}-$ sistemos (18) laisvujuc narių vektoriaus $\boldsymbol{\omega}_{0}=\left(\boldsymbol{\omega}^{T} 0^{T}\right)^{T}$ kovariacijų matrica.

Kovariacijų matrica $\boldsymbol{K}_{\omega_{0}}$ yra lygi

$$
\begin{aligned}
& \boldsymbol{K}_{\omega_{0}}=\mathrm{M}\left\{\left(\begin{array}{c}
\omega-\mathrm{M} \omega \\
0
\end{array}\right)\left(\begin{array}{c}
\omega-\mathrm{M} \omega \\
0
\end{array}\right)^{T}\right\}= \\
& \mathrm{M}\left(\begin{array}{cc}
\delta \omega \cdot \delta \omega^{T} & 0 \\
0 & 0
\end{array}\right)=\left(\begin{array}{cc}
\boldsymbol{K}_{\omega} & 0 \\
0 & 0
\end{array}\right),
\end{aligned}
$$

čia $\mathrm{M}$ - vidurkio (matematinès vilties) simbolis, $\delta \omega=\omega-\mathrm{M} \omega$.

Vektoriaus $\boldsymbol{\omega}$ kovariaciju matrica $\boldsymbol{K}_{\boldsymbol{\omega}}$ gaunama iš formulès:

$$
\boldsymbol{K}_{\omega}=\left(\boldsymbol{A}^{T} \boldsymbol{P}\right) \boldsymbol{K}_{L}\left(\boldsymbol{A}^{T} \boldsymbol{P}\right)^{T}=\sigma_{0}^{2} \boldsymbol{A}^{T} \boldsymbol{P A}=\sigma_{0}^{2} N
$$


čia $\boldsymbol{K}_{\boldsymbol{L}}=\boldsymbol{K}_{\Phi}=\sigma_{0}^{2} \boldsymbol{P}^{-1}-$ nešlio fazių dvigubujų skirtumų kovariacijų matrica, $\sigma_{0}-$ matavimo rezultato, kurio svoris lygus vienetui, standartinis nuokrypis.

Galutinè vektoriaus $\tilde{\boldsymbol{T}}_{0}$ kovariaciju matricos $\boldsymbol{K}_{\tilde{\boldsymbol{T}}_{0}}$ išraiška, įvertinus (22), (23):

$$
\begin{aligned}
& \boldsymbol{K}_{\tilde{\boldsymbol{T}}_{0}}=\sigma_{0}^{2}\left(\begin{array}{ll}
\boldsymbol{Q}_{11} & \boldsymbol{Q}_{12} \\
\boldsymbol{Q}_{21} & \boldsymbol{Q}_{22}
\end{array}\right)\left(\begin{array}{cc}
\boldsymbol{N} & 0 \\
0 & 0
\end{array}\right)\left(\begin{array}{ll}
\boldsymbol{Q}_{11} & \boldsymbol{Q}_{12} \\
\boldsymbol{Q}_{21} & \boldsymbol{Q}_{22}
\end{array}\right)= \\
& \sigma_{0}^{2}\left(\begin{array}{ll}
\boldsymbol{Q}_{11} \boldsymbol{N} \boldsymbol{Q}_{11} & \boldsymbol{Q}_{11} \boldsymbol{N} \boldsymbol{Q}_{12} \\
\boldsymbol{Q}_{21} \boldsymbol{N} \boldsymbol{Q}_{11} & \boldsymbol{Q}_{21} \boldsymbol{N} \boldsymbol{Q}_{12}
\end{array}\right) .
\end{aligned}
$$

Kovariacijų matricos $\boldsymbol{K}_{\widetilde{\boldsymbol{T}}_{0}}$ blokinè dalis

$$
\boldsymbol{K}_{\widetilde{T}_{0,11}}=\boldsymbol{K}_{\tilde{\boldsymbol{T}}}=\sigma_{0}^{2} \boldsymbol{Q}_{11} \boldsymbol{N} \boldsymbol{Q}_{11}
$$

apibūdina parametrų vektoriaus $\tilde{\boldsymbol{T}}$ tikslumą. Blokinè dalis $\boldsymbol{K}_{\tilde{\boldsymbol{T}}_{0,22}}=\sigma_{0}^{2} \boldsymbol{Q}_{21} \boldsymbol{N} \boldsymbol{Q}_{12}$ apibūdina koreliatų vektoriaus $\boldsymbol{k}$ tikslumą.

Standartinio nuokrypio $\sigma_{0}$ ịvertis skaičiuojamas pagal formulę:

$$
\sigma_{0}^{2} \approx m_{0}^{2}=\frac{1}{n-k_{0}} \boldsymbol{V}^{\boldsymbol{T}} \boldsymbol{P} \boldsymbol{V}
$$

čia $n=6 n_{e}, k_{0}=12 \cdot 3=36$ - parametrų skaičius.

Formulès (19), (20) rodo, kad tuo atveju, kai nèra taikomos sąlyginès lygtys (15), išlygintujuc parametrų vektoriaus $\tilde{\boldsymbol{T}}$ tikslumas įvertinamas kovariacijų matrica $\boldsymbol{K}_{\tilde{\boldsymbol{T}}}^{\prime}=\sigma_{0}^{2} \boldsymbol{N}^{-1}$.

Pagal formulę (20) matyti, kad $Q_{11, i i}>N_{i i}^{-1}$, t. y. tarp diagonaliujų narių egzistuoja nelygybè.

Taikydami formulę (25) galime tvirtinti, jog $\boldsymbol{K}_{\tilde{\boldsymbol{T}}, i i}=\sigma_{0}^{2}\left(\boldsymbol{Q}_{11} \boldsymbol{N} \boldsymbol{Q}_{11}\right)_{i i}>\boldsymbol{K}_{\tilde{\boldsymbol{T}}, i i}^{\prime}=\sigma_{0}^{2}\left(\boldsymbol{N}^{-1}\right)_{i i}$. Taigi pastaroji nelygybè rodo, kad išlygintujuc parametruc $\tilde{\boldsymbol{T}}_{\boldsymbol{i}}$ dispersijos $\quad \boldsymbol{K}_{\tilde{\boldsymbol{T}}, \boldsymbol{i}}=\boldsymbol{D} \tilde{\boldsymbol{T}}_{\boldsymbol{i}}$, kai taikomos papildomos sąlyginès lygtys (15), yra didesnès už dispersijas $\boldsymbol{K}_{\tilde{\boldsymbol{T}}, i i}^{\prime}=\boldsymbol{D}^{\prime} \tilde{\boldsymbol{T}}_{\boldsymbol{i}}$, gautas netaikant sąlyginių lygčių. Lygybès (20) blokinès dalies $\boldsymbol{Q}_{11}$ dedamoji $\boldsymbol{F} \boldsymbol{H}^{-1} \boldsymbol{F}^{\boldsymbol{T}}=\Delta \boldsymbol{N}^{-1}$ rodo, kokia dalimi padideja $\boldsymbol{N}^{-1}$ matricos elementai, apibūdinantys išlygintuju parametrų tikslumą, kai netaikomos sąlyginès lygtys.

\section{Išvados}

1. Jonosferos klaidu sistemingosioms komponentėms nustatyti siūlomas nešlio fazių dvigubujų skirtumu parametrinių lygčių kartu su papildomomis koordinačių prieaugių sąlyginèmis lygtimis variantas. Taikant sąlygines lygtis sumažèja išlygintujų parametrų reikšmių tikslumas, nes tam tikra matavimu informacijos dalis yra panaudojama papildomiems parametrams - koreliatams skaičiuoti.

2. Apskaičiuotų parametrų kovariacijų matricų išraiškos, gautos taikant ir netaikant papildomas sąlygines koordinačių prieaugių lygtis, rodo, kokia dalimi padidèja išlygintujų parametrų dispersijos, taikant sąlygines lygtis, palyginti su dispersijomis, kai sąlyginès lygtys netaikomos.

\section{Literatūra}

1. BAUER, M. Vermessung und Ortung mit Satelliten. Heidelberg: Wichmann, 1994. 274 S.

2. HOFMANN-WELLENHOF, B.; LICHTENEGGER, H. and COLLINS, J. Global Positioning System. In Theory and Practice. Wien, New York: Springer-Verlag, 1992. $326 \mathrm{p}$.

3. KOCH, K. R. Einführung in die Bayes-Statistik. SpringerVerlag, Berlin Heidelberg, 2000. 225 S.

4. LEICK, A. GPS Satellite Surveying. New York, Chichester, Brisbane, Toronto, Singapore: John Wiley and Sons, 1995. $352 \mathrm{p}$.

5. TEUNISSEN, P. J. G. An optimality property of the integer least-squares estimator. Journal of Geodesy, 1999, No 73. Berlin: Springer-Verlag, p. 275-284.

6. HANKEMEIER, P. Der Satellitenpositionierungsdienst SAPOS in Deutschland. Multifunktionale GNSSReferenzstationsysteme für Europa. Workshop von 4. 5. März 2002 in der Europäischen Akademie für städtische Umwelt. Berlin, S. 16-23.

7. YIH HWA HO; AHMAD FAIZAL MOHD; ZAIN MARDINA ABDULLAH; ABDUL GHAFFAR RAMLI; WAN SALWA; WAN HASSAN. Equatorial TEC Variations During the Geomagnetic Storm of July 15-17, 2000. In 2002 - the $27^{\text {th }}$ triennial General Assembly of the International Union of Radio Science. Maastricht, 2002.

8. GAO, Y.; and LIU, Z. Z. Precise Ionosphere Modeling Using Regional GPS Network Data. Journal of Global Positioning Systems, 2002, Vol 1, No 1, p. 18-24.

9. PULINETS, S. A. and LIU, J. Y. Ionospheric variability unrelated to solar and geomagnetic activity. Adv. Space Rec., 2004, 34, p. 1926-1933.

10. SKEIVALAS, J. Accuracy determination of the coordinates augmentations of GPS vectors by measuring double phase shifts of the carrier. Geodesy and Cartography (Geodezija ir kartografija), 2003, Vol XXIX, No 4, p. 115-118 (in Lithuanian).

11. SKEIVALAS, J. Usage of double carrier phase differences for ionospheric influence elimination in coordinates determination. Geodesy and Cartography (Geodezija ir kartografija), 2005, Vol XXXI, No 3, p. 88-91 (in Lithuanian).

Jonas SKEIVALAS. Prof, Doctor Habil. Vilnius Gediminas Technical University. Dept of Geodesy and Cadastre, Saulètekio al. 11, LT-10223 Vilnius, Lithuania. $\mathrm{Ph}+37052744$ 703, Fax +370 52744 705,

e-mail: jonas.skeivalas@ap.vgtu.lt.

Author of two monographs and more than 130 scientific papers. Participated in many intern conferences and research visits to the Finish Geodetic Institute.

Research interests: processing of measurements with respect to tolerances, adjustment of geodetic networks. 